\title{
Solar forcing of the tropical Pacific climate and impacts over North America for the last millennium
}

\author{
Amy C. Clement ${ }^{1}$, Julien Emile-Geay ${ }^{2}$, Richard Seager ${ }^{2}$, Mark Cane ${ }^{2}$ and Michael N. Evans ${ }^{3}$ \\ ${ }^{1}$ Rosenstiel School of Marine and Atmospheric Sciences, University of Miami, USA; aclement@rsmas.miami.edu \\ 2Lamont-Doherty Earth Observatory, Columbia University, Palisades, USA; julieneg@Ideo.columbia.edu, rich@ldeo.columbia.edu, \\ mcane@ldeo.columbia.edu \\ ²aboratory of Tree-Ring Research, University of Arizona, Tucson, USA; mevans@|trr.arizona.edu
}

\section{Introduction}

It is now well known that the state of the tropical Pacific climate has a large influence on the global climate, as evidenced by the interannual variations associated with the EI Niño/Southern Oscillation (ENSO) and its global teleconnections. If the mean state of the tropical Pacific were to undergo shifts on longer timescales, it is likely that such changes would also have global impacts. This possibility has prompted debate about whether the tropical Pacific has undergone changes over the 20th century that are akin to the warm phase (EI Niño) or cold phase (La Niña) of ENSO, and also whether such shifts will be part of the climate response to increased greenhouse gases (GHGs) in the future. At present, state-ofthe-art coupled ocean-atmosphere general circulation models (GCMs) simulate different responses in the tropical Pacific climate to increased GHGs, with some models predicting a decreased east/west sea surface temperature (SST) gradient (akin to El Niño), others predicting an increased gradient (akin to La Niña), and still others predicting no change (Collins et al., 2005). Given this uncertainty, it is reasonable to turn to the past to learn about how the tropical Pacific responded to climate forcing, and whether the influence of the tropical Pacific can be seen in past regional climate proxies around the globe.

\section{Modeling results}

In this paper, we present results from several recent studies, many of which have been supported under the National Science Foundation's Earth System History program, in order to illustrate how the tropical Pacific climate has responded to solar forcing over the last 1000 years. Figure 1a shows

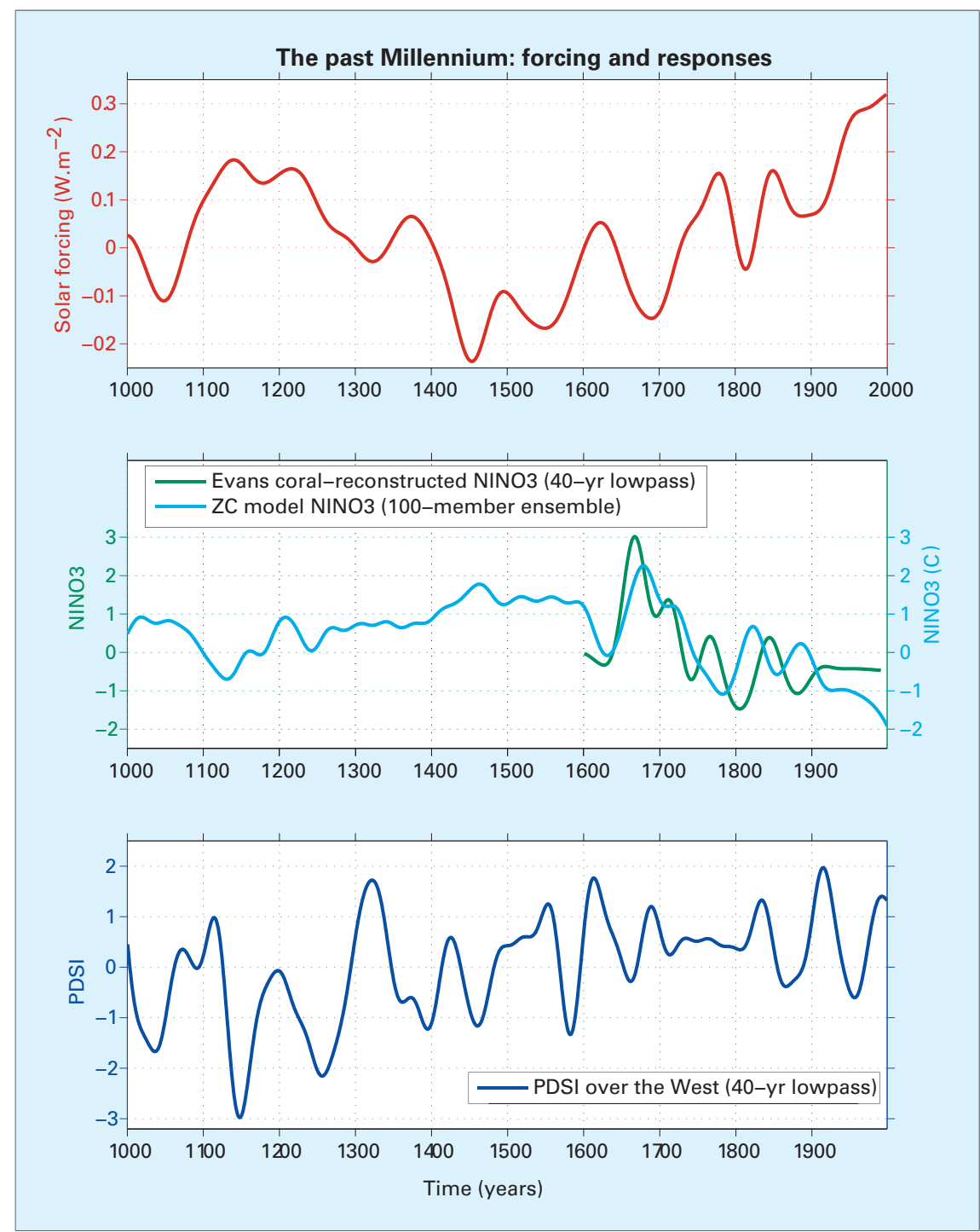

Figure 1: Top Panel: Solar forcing over the last millennium, from Crowley (2000). Units are $W^{-2}$. Middle Panel: NINO3 SST index simulated by the ZC model in response to the solar forcing shown in the top panel (blue curve). The green curve shows the NINO3 value reconstructed using the methodology of Evans et al. (2002) applied to a network of 65 corals (reported by Evans et al., 2001). Both curves are normalized and smoothed with a 40-year low-pass filter. Bottom panel: Palmer Drought Severity index for the western U.S. as reconstructed from the Cook et al. (2004) gridded data. Negative values indicate drought conditions and positive values wet conditions. The data are normalized and smoothed with a 40-year low-pass filter.

the solar forcing as reconstructed by Crowley (2000). This forcing is imposed on the Zebiak-Cane (ZC) coupled ocean-atmosphere model, which simulates anomalies about the current climate in the tropical Pacific. Results from a 100-member ensemble (in which the forcing is identical but initial conditions are varied slightly from member to member) are shown in Figure $1 b$ (blue line). There is a clear anti-correlation between the solar forcing and the value of NINO3 (average SST anomaly over the region $5^{\circ} \mathrm{S}$ $5^{\circ} \mathrm{N}$ and $150-90^{\circ} \mathrm{W}$ ) such that when the solar irradiance is higher, the mean NINO3 value is negative (akin to a La Niña with an increased eastwest gradient), and when irradiance 


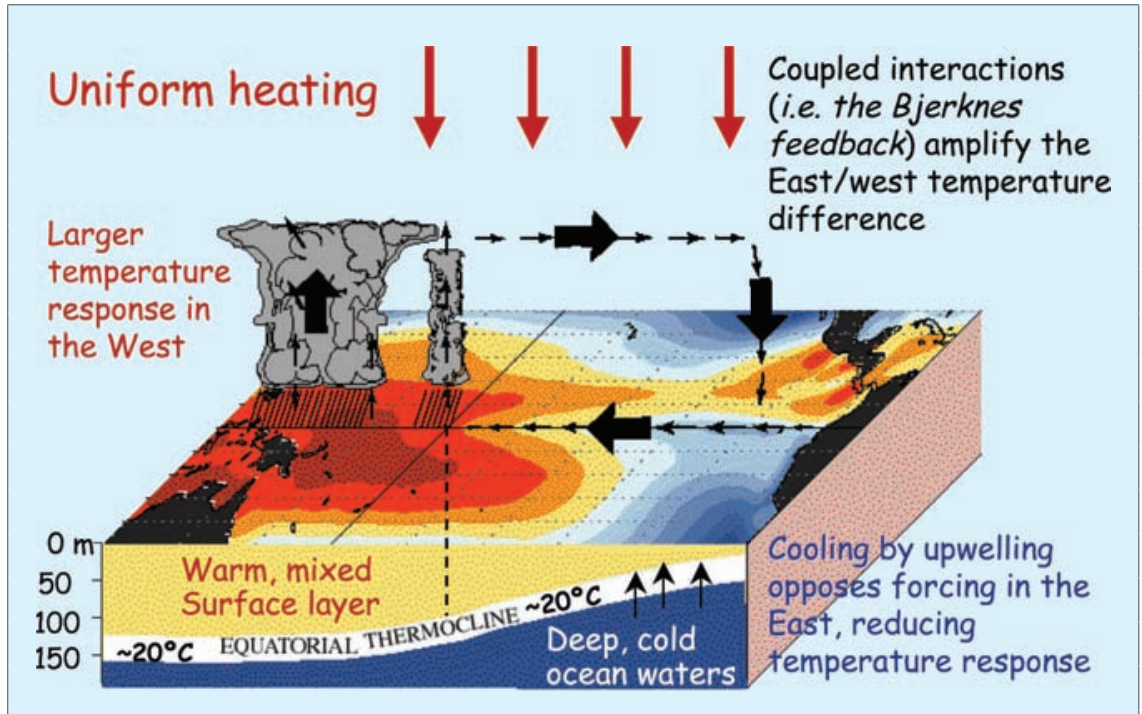

Figure 2: Schematic representation of the 'thermostat' mechanism (see text) proposed by Clement et al. (2006). Figure courtesy of Lowell Stott.

is lower, NINO3 is higher (akin to an El Niño with a decreased gradient). It should be noted that there is currently considerable debate as to the magnitude of the centennial timescale variations in the solar irradiance, so these results should be interpreted only qualitatively.

The model results can be explained by a mechanism that has been dubbed the ocean dynamical thermostat (Clement et al., 1996), in which a heating of the tropical Pacific ocean leads to a cooling of the NINO3 region (illustrated schematically in Fig. 2). This result arises from the different surface temperature response in the eastern and western Pacific: In the west, where the thermocline is deep, the response to surface heating is largely thermodynamic and the mixed layer adjusts with an increased temperature. In the east where the thermocline is shallow, cooling by vertical advection offsets the surface heating, producing a smaller temperature response. The increased zonal sea surface temperature (SST) gradient accelerates the trade winds, which leads to further thermocline shoaling and cooling by vertical advection in the east, further accelerating the winds. This 'climatological' Bjerknes feedback, akin to that which operates on interannual timescales, leads to a cooling of the eastern equatorial Pacific in response to a heating of the Basin. Is there any evidence of such behavior in the paleoclimate record?

\section{Paleoclimate observations}

An extremely important archive of past behavior of ENSO and the mean state of the tropical Pacific comes from both living and fossil corals. Evans et al. (2002) have used a network of coral records to reconstruct SST from the tropical Pacific over the last several centuries. The reduced space objective analysis methodology of Evans et al. (2002) was applied to a larger number of coral records (Evans et al., 2001), and the resulting NINO3 reconstruction is plotted in Figure 1b (green line). Agreement between independently-reconstructed NINO3 and model-simulated NINO3 is encouraging; both lines of evidence suggest a maximum value in the mid- to late-17th century, coinciding with the Maunder Minimum, and a shift towards lower values of NINO3 from that time until through the 20th century. There are, however, notable differences between the model and data on multi-decadal timescales which may be due to deficiencies in both products. We must assume that the interpretation of coral-reconstructed SST has fidelity on timescales longer than are available for statistical calibration. The model simulates a trend of decreasing NINO3 over the 20th century, while the data do not show such a trend, perhaps because changes in greenhouse gas concentrations are not modeled.

There are other coral records that support the picture of a warm eastern equatorial Pacific (or reduced east-west gradient) in the mid-17th to mid-18th century. Cobb et al. (2003) found relatively light values for $\delta^{18} \mathrm{O}$ (warm, fresh conditions) in corals from Palmyra Island during the 17th century. They also found relatively heavy values (cold, salty) during the 12th to 13th centuries, a time when the solar forcing was high. If the modern behavior of $\delta^{18} \mathrm{O}$ on interannual timescales is extended to the past, this would indicate a reduced east-west gradient for the 17th to 18th centuries, and an increased gradient for the earlier medieval period, consistent with the model results. Damassa et al. (2006) also showed that coral records from the western Indian ocean indicate that SSTs were warmer during the mid-17th to mid-18th century. Again, if the modern ENSO analogy is extended to the past, this would imply a reduced east-west gradient at that time, also consistent with the model results.

This collection of model results and coral data from the tropical Pacific appears to suggest that solar forcing has an influence on the tropical Pacific climate in a manner consistent with the ocean dynamical thermostat. The implications of this may extend beyond the Pacific Basin. Seager et al. (2005) and Herweijer et al. (2006a) have used observations and model simulations to argue that decadal timescale $\mathrm{La}$ Niña-like SST changes were responsible for the six severe multi-year North American droughts since the mid-19th century. Herweijer et al. (submitted) used a gridded drought reconstruction based on tree-ring data from Cook et al. (2004) to show the existence of 'mega-droughts' during the medieval period that had a spatial pattern very similar to modern droughts. They argued that the temporal drought variability was similar to that of the 20th century but that it occurred around a drier mean state, such that peri- 
ods of, for example, Dust Bowl level aridity, lasted for $20-40$ years. Graham et al. (submitted) have used proxies to estimate medieval SSTs and demonstrated that when they are used to force an atmospheric GCM, drought results over North America. The altered mean state of the medieval period, not only in North America but also in other ENSO sensitive regions (e.g., East Africa, northern South America, South Africa, the Sahel and the Indian ocean; Herweijer et al., submitted), is consistent with a solar-induced La Niña-like state in the tropical Pacific. The tree ring data also show that the Little Ice Age was a relatively wet period in the central U.S. compared with the earlier medieval period (Fig. 1c), consistent with a shift towards a reduced east-west gradient, as shown in Figure $1 \mathrm{~b}$.

\section{Final points}

Of course, a number of caveats apply here. First, model studies have shown that Atlantic SSTs exert an influence on central U.S. precipitation (Schubert et al., 2004; Seager et al., submitted; Sutton and Hodson, 2005), so there is no reason to believe that conditions in the tropical Pacific are a perfect predictor of central U.S. rainfall. It should also be noted that the observations of tropical Pacific SSTs are quite sparse prior to the 20th century, and coral data for the last 1000 years are critical to filling in these gaps. Finally, there is the issue of the magnitude of solar irradiance changes. While the $Z C$ model is fairly sensitive to even small solar forcing (Emile-Geay et al., accepted), if the mid-range value of $0.5 \mathrm{Wm}^{-2}$ is accepted, the model response is quite small $\left(\sim 0.15^{\circ} \mathrm{C}\right)$. Thus, while the linkages explored here might have qualitative support from models and paleoclimate observations, it is difficult to argue for such large quantitative changes in the climate system from solar forcing alone. Thus remains the centuries-old problem of why the climate response to solar forcing appears to be so large. Perhaps the tropical Pacific is part of the answer but it may not be the whole story.

\section{Note}

Data used in the study can be found in the 'data' section of the authors research page at http://www.Ideo.columbia.edu/ julieneg/ research.html.

\section{References \\ Clement, A.C., Seager, R., Cane, M.A., and Zebiak, S.E., 1996: An ocean dynamical thermostat. J. Climate, 9: 2190-2196. \\ Emile-Geay, J., Cane, M., Seager, R., Kaplan, A., and Almasi, P., accepted: ENSO as a mediator of the solar influence on climate, Paleoceanography. \\ Evans, M.N., Kaplan, A. and Cane, M.A., 2002: Pacific sea surface temperature field reconstruction from coral delta 0-18 data using reduced space objective analysis. Paleoceanography, 17, Art. No. 1007. \\ Herweijer, C., Seager, R. and Cook, E.R., 2006a: North American droughts of the mid to late nineteenth century: a history, simulation and implication for Mediaeval drought, The Holocene, 16(2): 159-171. \\ Seager, R., submitted: The turn of the century drought across North America: Dynamics, global context and prior analogs. J. Climate.}

For full references please consult:

www.pages-igbp.org/products/newsletters/ref2006_2.html

\title{
The mystery interval 17.5 to 14.5 kyrs ago
}

\author{
George H. Denton ${ }^{1}$, Wallace S. Broecker ${ }^{2}$ and Richard B. Alley ${ }^{3}$ \\ 1Department of Earth Sciences and Climate Change Institute, University of Maine, Orono, USA; gdenton@maine.edu \\ 'Lamont-Doherty Earth Observatory, Columbia University, Palisades, USA \\ ${ }^{3}$ Pennsylvania State University, University Park, USA
}

The time period between the beginning of Heinrich event \#1 $(\mathrm{H}-1)$ and the onset of the Bølling/Allerød rivals the Younger Dryas in importance to our understanding of how the planet responds to abrupt mode switches. This interval also constitutes the onset of the most recent termination, arguably the most fundamental climate shift of the last 100-kyr glacial cycle. As some of the responses during this time appear to be mutually contradictory, we term it the "Mystery Interval".

\section{Key observations}

Notable events during the 3000year-long Mystery Interval are as follows (Fig. 1).

-The H-1 iceberg armada was discharged into the North Atlantic
Ocean (Bond et al., 1992; Hemming, 2004).

- Export of ${ }^{231} \mathrm{~Pa}$ from the Atlantic to the Southern Ocean appears to have come to a halt, signaling a shutdown of North Atlantic meridional overturning circulation (McManus et al., 2004).

-The northern Atlantic Ocean and the Mediterranean Sea became unusually cold (Bard et al., 2000; Cacho et al., 2001).

- Conditions in Greenland were heavily weighted toward hypercold winters (stadial GS-2a; Denton et al., 2005).

- Northwestern Europe was similarly dominated by hypercold winters (Late-Pleniglacial; Renssen and Isarin, 2001).
-The Asian monsoons were notably weakened (Wang et al., 2001).

- The Atlantic Intertropical Convergence Zone (ITCZ) was locked into a southerly position (Peterson et al., 2000; Lea et al., 2003).

- Temperate mountain glaciers in both hemispheres underwent major recession that began about 17.5 kyr (Denton et al., 1999; Schaefer et al., 2006). By $14.5 \mathrm{kyr}$ at the end of the Mystery Interval, Swiss mountain glaciers had withdrawn to the inner Alps (Schlüchter, 1988).

- Closed-basin lakes in North America's Great Basin reached their greatest size (Benson, 1993; Garcia and Stokes, 2000). 